\title{
PREVALENCE OF HYPERTENSION AND DETERMINATION OF ITS RISK FACTORS IN KORANGRAPADY, UDUPI DISTRICT, COASTAL KARNATAKA, INDIA
}

\author{
STEFFI VEIENTLENA*, PRABU P \\ Department of Computer Science, Christ (Deemed to be University), Bengaluru - 560 029, Karnataka, India. \\ Email: steffi.veientlena@mca.christunivesity.in
}

Received: 11 January 2017, Revised and Accepted: 17 February 2018

\section{ABSTRACT}

Objective: Hypertension is a global public health problem that estimates about $4.5 \%$ of overall disease burden. It is a general health challenge in economically developing and developed countries. High blood pressure prevalence is increased from $11.2 \%$ to $28 \%$ ( $p<0.001$ ) and $23-42.2 \%$ in rural and urban area according to the study done in Delhi for about 20 years. It is one of the important risk factors of cardiovascular disease, which is associated with morbidity and mortality. The aim was to identify the significant correlates of hypertension in a rural village in south India.

Methods: Data were collected through a door-to-door survey among the residents of the village. Data collected was related to demographics and anthropometric measures. Blood pressure was measured with the help of the medical supervisor. Data were analyzed using Chi-square test for comparison between attributes. The potential hazard factor of hypertension was found by performing binary logistic regression model.

Result: Of 299 participants considered for the study, 50 were hypertensive contributing to the overall prevalence of $16.72 \%$ with $95 \%$ confidence interval of $0.1292-0.2137$, in which females have the prevalence rate of $17.8 \%$ and males with the prevalence rate of $15.5 \%$. The study outcome identified education level, occupation, and family history of hypertension is the predicted risk factors.

Conclusion: The high blood pressure prevalence is low and comparable with the studies conducted in other rural regions of India. More studies are, however, required to decide the appropriation and determinants of hypertension in different parts of this region.

Keywords: Prevalence, Hypertension, Risk Factors, Cross-sectional Study, Rural India, Karnataka, India.

(C) 2018 The Authors. Published by Innovare Academic Sciences Pvt Ltd. This is an open access article under the CC BY license (http://creativecommons. org/licenses/by/4. 0/) DOI: http://dx.doi.org/10.22159/ajpcr.2018.v11i6.24727

\section{INTRODUCTION}

Hypertension is a leading cause of mortality rates in most of the developing countries [1]. According to the World Health Organization (WHO) about $40 \%$ of the population aged 25 years and above had hypertension in 2008 [2], and statistical reports estimate up to 4.5 million deaths, but $57 \%$ of stroke deaths and $24 \%$ of coronary heart disease in India is caused due to hypertension [3]. In 2020, cardiovascular diseases will be the largest cause of death in India. Until recently, hypertension is not given importance in most part of India. The condition of hypertension is now reported because it is the major cause for cardiovascular diseases. In late decades, it has turned out to be progressively certain that the improvement of stroke, ischemic coronary illness, and renal failure has been credited by hypertension. India is a highly populated nation its prevalence of hypertension is increasing in both rural and urban area. In India, most of the people with hypertension are unaware of their diagnosis. The control and prevention of hypertension has not received continuous or constant attention by India. The before study of hypertension and its prevalence shows that in India hypertension is high in urban areas and less in rural area. Past examination demonstrates the distinguished hazard factor for hypertension in Indians, which incorporate high weight, obesity, age, alcohol consumption, way of life, and stress. However, as rural India keeps on experiencing statistic progress, the commitment of such hazard components to hypertension in India is probably going to change. Concentrating on these progressions may give more knowledge into how best to allot resources to decrease the burden of hypertension on India's health framework. The study aims at identifying the high blood pressure prevalence and its significant correlates with the collected data in small rural region called Korangrapady in Udupi district, Karnataka state, India. Hypertension is an asymptotic condition; side effects do not arise unless the complications develop which result in differed conclusion and treatment, particularly among the uneducated and unexplained social groups such as rural Indian population. The dependable data about the prevalence of hypertension are essential to the improvement of national and local level health arrangements for counteractive action and control of hypertension at most punctual stage. There is shortage of community-level information about the prevalence of hypertension and its hazard factors in rural population of India. Hence, this study was directed with the target of discovering prevalence of hypertension and its risk hazards in a small group of rural population of coastal India. Several studies have been done to understand the prevalence of hypertension in rural and also urban India. An examination led in provincial Delhi, India demonstrates that pervasiveness of hypertension was $14.1 \%$ in study subjects [2]. Hypertension was essentially higher among people over 35 years than those under 35 years. Hypertension was all together higher in participants who take liquor and in subjects with raised aggregate cholesterol level. The study also concludes by stressing that there is a significant burden of hypertension in rural areas in Delhi, India [2]. Another examination directed in coastal region of Karnataka, India, which is comparable locale considered to our study demonstrates that high blood pressure prevalence was more among males as considered to that of females. Advancing age, male sexual orientation, current diabetic status, central obesity, and family history of hypertension were distinguished as significant correlates of hypertension by multivariate logistic regression [18]. Related study conducted in rural areas of Davangere, Karnataka, India, shows that among all the participants the prevalence of hypertension was $18.3 \%$. The study also states that the prevalence of hypertension was more in male than in female [21]. From this study, it was apparent that hypertension is not only a worry of urban populace, yet additionally a matter of verbal confrontation in rural province of India. Most of the hypertensive was not aware of 
their blood pressure, and the treatment rate was poor followed by control of hypertension [13]. Similar study conducted by Vinod et al. in Amravati, district of Maharashtra, India, shows that the prevalence of hypertension was $13.4 \%$ [3]. Older age and body mass index (BMI) was significantly higher among the hypertensive compared with the normotensives. Tobacco and alcohol were significantly associated with hypertension [3]. The related examination conducted in Maharashtra to identify the prevalence of hypertension in rural India also shows that the prevalence rate was $7.24 \%$. The study also identifies that the prevalence of hypertension increases with increase in age, BMI, salt intake, alcohol consumption, and diabetes mellitus [15].

\section{MATERIALS AND METHODS}

\section{Materials}

Considering the related investigation performed in rural India, it is to be comprehended that high blood pressure prevalence is a fluctuating variable in various part of rural India. Results have demonstrated that the prevalence factor is high in some rural India and extensively low in other rural parts of India. Existing studies also showed that the high blood pressure hazard factors change in different studies and are not same. The current study is necessary for following reasons:

- To identify the extinct of hypertension in the study locale.

- To study the high blood pressure prevalence in the examination area.

- To identify the potential risk factor associated with hypertension in study population.

\section{Methods}

\section{Sample selection}

Korangrapady is a small town situated in Udupi region in Karnataka state with the number of inhabitants of 4944 as per the 2011 statistics. A cross-sectional examination was directed in this region in April 2017. The study included 300 permanent residents belonging to the region aged 20 years and above. All members belonging to one particular family are taken into consideration. All the participants considered in the study are considered to be rural population of India. Ethical clearance was obtained from the institution before the start of examination.

Data regarding significant correlates of hypertension were collected through a door-to-door survey in this study area. A questionnaire uniquely arranged for this examination was utilized for data collection. The questionnaire was structured into three legitimate areas (sociodemography attributes, behavioral and medical-related inquiries, and anthropometric measurements). The WHO STEPS strategy was adopted to plan on choose of behavioral and lifestyle characteristics and estimates of weight and height. This is the first study that has been conducted in this area to identify the determinants of hypertension. The questionnaire was produced in English language and was managed to administer in Kannada (the neighborhood language) to the participants. Data were collected with the help of a team of two people (1 researcher and 1 medical supervisor). The team was prepared and trained in the methodology of the survey. The survey recorded fundamental demographic data such as age, sex, and education for every individual from the family. Age was cross-checked with individual's birth certificate and the individuals with no birth declaration certificate age were computed using birth year and affirmed utilizing memory prompts. For those aged 20 years and more, data on tobacco utilize and alcohol admission and a history of hypertension were recorded. Diabetes was recorded as a categorical factor by examining participant's self-knowledge about the diabetic disease.

\section{Measurements}

Blood pressure

Blood pressure was measured in a sitting position with the help of the standard measuring instrument. Twice blood pressure has been measured with the interval of $5 \mathrm{~min}$, the mean of both the measurements is taken into consideration for the study. Hypertension was characterized as BP $\geq 140 \mathrm{mmHg}$ systolic and $\geq 90 \mathrm{mmHg}$ diastolic
BP. This is as per the joint national committee $\mathrm{V}$ criteria [4]. Participants having systolic and diastolic blood pressure less than the standard reading is considered to be normotensive, and participants with higher reading are considered to be hypertensive.

\section{Anthropometric measurements}

Weight was measured utilizing a standard measuring scale in kilograms and was recorded to the closest of $0.5 \mathrm{~kg}$. Height was measured in a standing position shoes ousted by utilizing measuring tape. Waist estimations were taken utilizing a standard measuring tape. BMI was computed utilizing weight in $\mathrm{kg}$ divided by height in meter squared. BMI $>25 \mathrm{~kg} / \mathrm{m}^{2}$ is characterized overweight. Abdominal obesity was characterized to be present when waist circumference $\geq 90 \mathrm{~cm}$ in males and waist circumference $\geq 80 \mathrm{~cm}$ in females.

\section{Sociodemographic factors}

The study incorporated the estimation of sociodemographic and behavioral factors such as smoking, alcohol consumption, vegetable and fruit intake, daily exercise routine, family history of hypertension, prior health examination of hypertension, education, and occupation. These covariates attributes of hypertension were collected through questionnaire. Categorical variables are communicated as absolute number, and continuous variable are communicated as mean and standard deviation (SD).

\section{Statistical methods}

Statistical analysis was done using bivariate methods. Data were tabulated and cross-tabulated and analyzed statistically. Chi-square test is used when confronting groups. The prevalence of hypertension was calculated as a number of participants considered as hypertensive by total number of participants. The overall prevalence of the study was calculated.

$$
\text { Prevalence }=\frac{\text { Noof hypertensive }}{\text { Total noof participants }}
$$

The prevalence of hypertension was calculated with respect to each of the covariates to understand the contribution of each factor to hypertension. The association of hypertension with sociodemographic factors was surveyed by contrasting the commonness of hypertension and individuals with and without these hazard factors. Binary logistic regression model analysis was used to distinguish the potential hazard factor of hypertension.

\section{$\log _{\text {it }}(\mathrm{P})=\log [\mathrm{P} / 1-\mathrm{P}]$}

The potential hazard factor with $\mathrm{p}<0.05$ is held in the examination. Odds ratio (OR) with $95 \%$ confidence interval (CI) is reported. All the measurable analysis was done using Statistical Package for the Social Sciences.

\section{RESULTS}

Of 4944 residents of the village, a total of 299 were included in the study. The participants considered in the study were all above 20 years of age. Among the respondents of the study, 142 (47.5) were females and 157 (52.5) were males. Most of the participants were within the age group of 40-59 years. The mean age of the participants was 43 years. There were a total of $24(8.02 \%)$ respondents who were known hypertensive and were under medication and were 26 (8.6\%) respondents who were newly diagnosed and did not know that they had hypertension.

Only $47 \%$ of the participants have obtained secondary education and more. Most of the participants 92 (30.8\%) had private job. Of all respondents, $23(7.7 \%)$ were reported as everyday alcohol users and $89(29.8 \%)$ participants are reported as smokers. Among all the participants, $173(59.6 \%)$ had a BMI above 25 or higher. Diabetes and family history of hypertension were collected through self-reporting of the participants. 
Table 1: Sociodemographic attributes, medical-related inquiries, measurements, and behavioral information characteristics of adults 20 years and above

\begin{tabular}{|c|c|c|}
\hline S. No. & Characteristics & $n=299(\%)$ \\
\hline \multirow[t]{4}{*}{1} & Age & \\
\hline & $20-39$ & $127(42.5)$ \\
\hline & $40-59$ & $141(47.2)$ \\
\hline & $60+$ & $31(10.4)$ \\
\hline \multirow[t]{3}{*}{2} & Gender & \\
\hline & Male & $157(52.2)$ \\
\hline & Female & $142(47.4)$ \\
\hline \multirow[t]{5}{*}{3} & Education & \\
\hline & No education & $25(8.3)$ \\
\hline & Primary & 131 (43.8) \\
\hline & Secondary & $94(31.4)$ \\
\hline & Higher & $49(16.4)$ \\
\hline \multirow[t]{6}{*}{4} & Occupation & \\
\hline & Unemployed & 65 (21.7) \\
\hline & Student & $23(7.7)$ \\
\hline & Government employee & $78(26.1)$ \\
\hline & Private employee & $92(30.8)$ \\
\hline & Own business & $41(13.7)$ \\
\hline \multirow[t]{3}{*}{5} & Health examination & \\
\hline & Yes & $65(21.7)$ \\
\hline & No & $234(78.3)$ \\
\hline \multirow[t]{6}{*}{6} & Family history of diabetes & \\
\hline & No & $139(46.5)$ \\
\hline & Parents & $53(17.7)$ \\
\hline & Brother and sister & $50(16.7)$ \\
\hline & Grandparents & $16(5.4)$ \\
\hline & Other & $41(13.7)$ \\
\hline \multirow[t]{3}{*}{7} & Daily exercise (30 min) & \\
\hline & Yes & $160(53.5)$ \\
\hline & No & $139(46.5)$ \\
\hline \multirow[t]{4}{*}{8} & Vegetable and fruit intake & \\
\hline & Everyday & $169(56.5)$ \\
\hline & Weekly & $50(16.7)$ \\
\hline & Twice a week & $80(26.8)$ \\
\hline \multirow[t]{3}{*}{9} & Smoke & \\
\hline & Yes & 89 (29.8) \\
\hline & No & $210(70.2)$ \\
\hline \multirow[t]{5}{*}{10} & Alcohol & \\
\hline & No & $206(68.9)$ \\
\hline & Daily & $23(7.7)$ \\
\hline & Weekly & 49 (16.7) \\
\hline & Monthly & $21(7.0)$ \\
\hline \multirow[t]{3}{*}{11} & BMI & \\
\hline & $<25$ (normal) & $126(40.4)$ \\
\hline & $>25$ (obesity) & $173(59.6)$ \\
\hline
\end{tabular}

*Systolic blood pressure $>140$ and diastolic blood pressure $>90$, BMI: Body mass index $\left(\mathrm{Kg} / \mathrm{m}^{2}\right)$, n: No of respondents

\section{Prevalence of hypertension}

The sociodemographic and behavioral information characteristics of the study population are shown in Table1. Of all participants, 50 were considered to be hypertensive giving a prevalence of 16.72 with $95 \%$ CI of $0.12-0.21$. The average systolic blood pressure of hypertensive participants was 145.52 (SD 5.03) and the average diastolic blood pressure of hypertensive participants was 106.62 (15.12). Whereas in normal hypertensive respondents, the average systolic blood pressure was 128.59 (SD 8.74) and average diastolic blood pressure was 87.75 (SD 12.98).

According to Table 2 the prevalence of hypertension is slightly higher in females $17.8 \%$ than in males $15.5 \%$. The study also showed that the prevalence of hypertension was higher among the participants aged 20-39 years $18.1 \%$. Participants with hypertension were significantly older with the average age of 42.6 (SD 12.65). Prior health examination of hypertension had no difference in the prevalence of hypertension. Participants with hypertension also had an average greater BMI of 25.19 compared to the participants without hypertension 23.16 . The prevalence
Table 2: Prevalence of hypertension in Korangrapady, Udupi, India, 2016-2017 n=299

\begin{tabular}{|c|c|c|c|c|}
\hline S. No. & Characteristics & $\mathbf{n}$ & Prevalence (\%) & CI $(95 \%)$ \\
\hline \multirow[t]{4}{*}{1} & Age & & & \\
\hline & $20-39$ & 23 & 18.1 & $0.118-0.259$ \\
\hline & $40-59$ & 23 & 16.3 & $0.106-0.285$ \\
\hline & $60+$ & 4 & 12.9 & $0.036-0.298$ \\
\hline \multirow[t]{3}{*}{2} & Gender & & & \\
\hline & Male & 22 & 15.5 & $0.100-0.225$ \\
\hline & Female & 28 & 17.8 & $0.122-0.247$ \\
\hline \multirow[t]{5}{*}{3} & Education & & & \\
\hline & No education & 1 & 04.3 & $0.001-0.219$ \\
\hline & Primary & 32 & 24.4 & $0.173-0.437$ \\
\hline & Secondary & 9 & 09.6 & $0.045-0.174$ \\
\hline & Higher & 7 & 14.3 & $0.059-0.272$ \\
\hline \multirow[t]{6}{*}{4} & Occupation & & & \\
\hline & Unemployed & 7 & 10.8 & $0.044-0.209$ \\
\hline & Student & 5 & 21.7 & $0.075-0.437$ \\
\hline & $\begin{array}{l}\text { Government } \\
\text { employee }\end{array}$ & 13 & 14.1 & $0.077-0.230$ \\
\hline & Private employee & 14 & 17.9 & $0.102-0.283$ \\
\hline & Own business & 11 & 26.8 & $0.142-0.429$ \\
\hline \multirow[t]{4}{*}{5} & Health & & & \\
\hline & examination & & & \\
\hline & Yes & 11 & 16.9 & $0.088-0.283$ \\
\hline & No & 39 & 16.7 & $0.121-0.221$ \\
\hline \multirow[t]{6}{*}{6} & $\begin{array}{l}\text { Family history of } \\
\text { diabetes }\end{array}$ & & & \\
\hline & No & 14 & 10.1 & $0.056-0.163$ \\
\hline & Parents & 19 & 35.8 & $0.231-0.502$ \\
\hline & $\begin{array}{l}\text { Brother and } \\
\text { sister }\end{array}$ & 10 & 20.0 & $0.100-0.337$ \\
\hline & Grandparents & 3 & 18.8 & $0.040-0.456$ \\
\hline & Other & 4 & 09.8 & $0.027-0.231$ \\
\hline \multirow[t]{3}{*}{7} & $\begin{array}{l}\text { Daily } \\
\text { exercise (30 min) }\end{array}$ & & & \\
\hline & Yes & 29 & 18.1 & $0.125-0.250$ \\
\hline & No & 21 & 15.1 & $0.096-0.222$ \\
\hline \multirow[t]{4}{*}{8} & $\begin{array}{l}\text { Vegetable and fruit } \\
\text { intake }\end{array}$ & & & \\
\hline & Everyday & 22 & 13.0 & $0.083-0.190$ \\
\hline & Weekly & 5 & 10.0 & $0.033-0.218$ \\
\hline & Twice a week & 23 & 28.7 & $0.192-0.400$ \\
\hline \multirow[t]{3}{*}{9} & Smoke & & & \\
\hline & Yes & 19 & 21.3 & $0.134-0.313$ \\
\hline & No & 31 & 14.8 & $0.103-0.203$ \\
\hline \multirow[t]{5}{*}{10} & Alcohol & & & \\
\hline & No & 37 & 18.0 & $0.130-0.239$ \\
\hline & Daily & 4 & 17.4 & $0.050-0.388$ \\
\hline & Weekly & 6 & 12.2 & $0.046-0.248$ \\
\hline & Monthly & 3 & 14.3 & $0.030-0.363$ \\
\hline \multirow[t]{3}{*}{12} & Diabetes & & & \\
\hline & Yes & 28 & 19.0 & $0.130-0.263$ \\
\hline & No & 22 & 14.5 & $0.093-0.211$ \\
\hline
\end{tabular}

Hypertension is defined as individuals those who had *systolic blood pressure $>140$ and diastolic blood pressure $>90, \mathrm{CI}$ : Confidence interval, n: No of respondents

of hypertension was greater among the participants with smoking habits $21.3 \%$ and also among the participants with everyday alcohol consumption $17.4 \%$. Hypertension prevalence was more among participants who had a habit of less consumption of vegetables and fruits $28.7 \%$. Participants with diabetes had higher prevalence of hypertension $19 \%$ than with participants recorded with negative diabetes. The prevalence of hypertension was high among the members who had a propensity for day-by-day alcohol consumption contrasted with the participants having week-by-week and month-by-month propensities for alcohol consumption.

Factors associated with hypertension

of all the covariates considered for the study, the factors found to be significantly associated with hypertension include educational 
qualifications of the participants, occupation, BMI, vegetable and fruit intake, and family history of hypertension. Participants with higher level of education were more likely to be hypertensive compared to participants with primary and secondary or no formal education with an $\mathrm{OR}=0.293(0.082-1.045)$. BMI was significantly associated with hypertension with $\mathrm{OR}=0.824(0.692-0.982)$. Participants having own business their occupation are more likely to have hypertension with $\mathrm{OR}=0.250(0.074-0.848)$ than with participants with other firm of employment. Vegetable and fruit intake habits of the participants have significantly influenced the hypertension with $\mathrm{p}=0.036$. Family history of hypertension was significantly associated with hypertension with $\mathrm{p}=0.023$. Table 3 summarizes the illustration of following risk factors associated with hypertension.

\section{DISCUSSION}

Hypertension is one of the main sources of death globally. It builds the danger of heartsickness, stroke, kidney failure, and many other diseases according to global status report on non-communicable disease 2010 [6]. The study conducted by Anchala et al. shows the overall prevalence of hypertension in India was $29.8 \%$, and there was significant difference in hypertension prevalence in rural India and urban India [7]. The prevalence rate of hypertension in India is lesser compared to the study conducted in China by Wei et al. (41\%) [8]. The prevalence of hypertension in rural India is slightly less compared to the prevalence of hypertension in urban India.

This study was conducted in Korangrapady a small rural area in Udupi district, coastal Karnataka, India. The overall prevalence of hypertension of the study was $16.72 \%$ which is less comparing to the study conducted by Parthaje et al., 29.6\% in an urban South India [9]. The study was comparable with the study conducted by Saxena et al., 18\% in rural coastal Karnataka [5]. The several studies conducted in rural India show the average prevalence of hypertension has 18.6\% [10-13]. Moreover, certain studies conducted also show lower prevalence of hypertension compared to our study with an average prevalence rate of $13.7 \%$ and $7.24 \%[14,15]$. The prevalence of hypertension is slightly higher in females (17.8\%) than in males (15.55). This shows that there is no much difference between the prevalence rate of male and female in the study. All other study conducted shows the prevalence of hypertension in male is higher than the prevalence of hypertension in females. The prevalence of hypertension was found to be less compared to that of Kerala, which is similar to coastal area with respect to dietary habits, occupation, and higher literacy rate [16,17]. In cross-sectional study, the prevalence of hypertension varies with respect to selection criteria of the study subjects, number of samples considered for the study and the region considered for the study.

The potential risk factors of the study include education level, occupation, BMI, vegetable and fruits intake, and family history of hypertension. BMI was one of the significantly associated risk factors of the current study, which is similar to the study conducted in rural area of Maharashtra by Vinod et al. [18]. Family history of hypertension is also shown as the potential risk factor. This predictor also acts as a strong predictor of hypertension in this region because the study conducted by Rao et al. also shows family history of hypertension is a potential risk factor in coastal region of Karnataka [19]. The study also shows that occupation which is indirectly associated with income and stress level is also a predictor of hypertension in this region. As many studies agreed that there is an association between age and hypertension [20-22] as age increases the risk of having hypertension

Table 3: Risk factor analysis of hypertension

\begin{tabular}{|c|c|c|c|c|c|c|}
\hline S. No. & Characteristics & Total & Hypertension & OR & CI (95\%) & $\mathbf{p}$ \\
\hline \multirow[t]{4}{*}{1} & Age & & & & & \\
\hline & 20-39 & 127 & $23(18.1)$ & - & - & 0.481 \\
\hline & $40-59$ & 141 & $23(16.3)$ & 0.498 & $0.091-2.729$ & 0.422 \\
\hline & $60+$ & 31 & $4(12.9)$ & 0.397 & $0.086-1.828$ & 0.236 \\
\hline \multirow[t]{3}{*}{2} & Gender & & & & & \\
\hline & Male & 157 & $22(15.5)$ & 0.853 & $0.341-2.132$ & 0.733 \\
\hline & Female & 142 & $28(17.8)$ & - & - & - \\
\hline \multirow[t]{4}{*}{3} & Education & & & & & \\
\hline & Primary & 131 & $32(24.4)$ & 0.315 & $0.025-3.952$ & 0.371 \\
\hline & Secondary & 94 & $9(9.6)$ & 1.21 & $0.357-4.110$ & 0.758 \\
\hline & Higher & 49 & $7(14.3)$ & 0.310 & $0.087-1.106$ & $0.041^{*}$ \\
\hline \multirow[t]{4}{*}{4} & Occupation & & & & & \\
\hline & Student & 23 & $5(21.7)$ & 0.319 & $0.089-1.148$ & 0.080 \\
\hline & Private employee & 92 & $14(17.9)$ & 0.326 & 0055-1.935 & 0.217 \\
\hline & Government employee & 78 & $13(14.1)$ & 0.436 & $0.124-1.535$ & 0196 \\
\hline 5 & Self employed & 41 & $11(26.8)$ & 0.271 & $0.080-0.921$ & $0.036^{*}$ \\
\hline 6 & BMI & 299 & $50(16.72)$ & 0.807 & $0.710-0.917$ & $0.001^{* *}$ \\
\hline \multirow[t]{4}{*}{7} & Vegetable and fruit intake & & & & & \\
\hline & Everyday & 169 & $22(13.0)$ & - & - & $0.037 *$ \\
\hline & Weekly & 50 & $5(10.0)$ & 0.356 & $0.142-1.895$ & $0.028^{*}$ \\
\hline & Twice a month & 80 & $23(28.7)$ & 0.216 & $0.071-0.957$ & $0.043 *$ \\
\hline \multirow[t]{5}{*}{8} & Family history of hypertension & & & & & \\
\hline & Parent & 53 & $19(35.8)$ & 0.410 & $0.100-1.684$ & 0.216 \\
\hline & Brother/sister & 50 & $10(20.0)$ & 4.553 & $1.109-18.69$ & $0.035^{*}$ \\
\hline & Grandparent & 16 & $3(18.8)$ & 1.375 & $0.306-6.222$ & 0.676 \\
\hline & Other & 41 & $4(9.8)$ & 0.522 & $0.074-4.108$ & 0.562 \\
\hline \multirow[t]{3}{*}{9} & Smoke & & & & & \\
\hline & Yes & 89 & $19(21.3)$ & 0.501 & $0.191-1.314$ & 0.160 \\
\hline & No & 210 & $31(14.8)$ & - & - & - \\
\hline \multirow[t]{5}{*}{10} & Alcohol & & & & & \\
\hline & No & 206 & $37(18.0)$ & - & - & 0.349 \\
\hline & Daily & 23 & $4(17.4)$ & 1.958 & $0.399-9.613$ & 0.408 \\
\hline & Weekly & 49 & $6(12.2)$ & 0.889 & $0.095-8.327$ & 0.918 \\
\hline & Twice a week & 21 & $3(14.3)$ & 0.731 & $0.119-4.506$ & 0.736 \\
\hline
\end{tabular}

${ }^{*} \mathrm{p}<0.05$ is considered as statistically significant, ${ }^{* *}$ systolic blood pressure $>140$ and diastolic blood pressure $>90$, CI: Confidence interval, BMI: Body Mass Index (Kg/m²). OR: Odds ratio 
is high. The current study shows that the prevalence of hypertension is high among the participants aged 20-39 years than among with higher age. This indicates that hypertension is rapidly growing in younger generation in this area. The study also showed the association between education level and hypertension. The prevalence of hypertension was high among the participants with primary level of education $(32 \%)$. This may be due to lack of knowledge about hypertension and no proper medication taken. Utilization of vegetable and organic product is likewise a critical factor associated with hypertension. The prevalence of hypertension was high with members having twice every week utilization of vegetable and organic products. This indicates that hypertension was high among the people who less utilizes vegetable and organic products than with the members who consume every day and weekly. This examination has potential constraints. Initially, being a cross-sectional one, it has inborn limitation; hypertension may have preceded some of the logical factors. Second, this examination is restricted to behavioral and physical estimations and did exclude biochemical estimations. Third, it just covered a part of the study population concerned with the study region.

\section{CONCLUSION}

There was a prevalence of $16.72 \%$ in rural coastal population of Udupi district, Karnataka, India. Asignificant proportion of $8.6 \%$ of participants were unaware of having the hypertension condition. Education level, occupation, family history of hypertension, and vegetable and organic food consumption are identified risk factor of hypertension in the study region. Our study is the only community-based examination directed in this locale to evaluate the burden and to distinguish the determinants of hypertension. Predominance of hypertension is generally low in rural India contrasting with that of urban India. The study affirms that developing health challenge of non-transferable disease has a general medical issue in rustic locale of coastal Karnataka. However, more cross-sectional investigations are requiring in this region with the specific goal to locate the extinct of hypertension and the hazard factors in different areas of provincial seaside district. Interventions aiming at reducing the risk factor recognized in this region are required and should also target the overall populace to diminish the hazard and risk of hypertension. A reliable exertion ought to be made to screen out new cases and to instruct individuals about the significance of being consistent to treatment.

\section{REFERENCES}

1. Olack B, Wabwire-Mangen F, Smeeth L, Montgomery JM, Kiwanuka N, Breiman RF, et al. Risk factors of hypertension among adults aged 35-64 years living in an urban slum Nairobi, Kenya. BMC Public Health 2015;15:1251.

2. Kishore J, Gupta JN, Kohli C, Kumar N. Prevalence of hypertension and Determination of its risk factors in rural Delhi. Int $\mathrm{J}$ Hypertens 2016;2016:1-6.

3. Wasnik VR, Jawarkar AK. Prevalence of prehypertension and hypertension in rural area of Amravati District of Maharashtra, India. Int J Res Med Sci 2016;4:549-555.

4. Bansal SK, Saxena V, Kandpal SD, Gray WK, Walker RW, Goel D. The prevalence of hypertension and hypertension risk factors in a rural
Indian community: A prospective door-to-door study. J Cardiovasc Dis Res 2012;3:17-123.

5. Saxena T, Rajeev KH. Prevalence of hypertension in a rural community of coastal Karnataka: A cross sectional study. Int J Community Med Public Health 2017;4:2774-7.

6. WHO. Global Health Report on Non-communicable Disease. Report of World Health Organization Consultation. Geneva, Switzerland: World Health Organization; 2010. p. 894.

7. Anchala R, Kannuri NK, Pant H, Khan H, Franco OH, Di Angelantonio $\mathrm{E}$, et al. Hypertension in India: A systematic review and meta-analysis of prevalence, awareness and control of hypertension. J Hypertens 2014;32:1170-7.

8. Wei Q, Sun J, Huang J, Zhou HY, Ding YM, Tao YC, et al. Prevalence of hypertension and associated risk factors in Dehui city of Jilin province in china. J Hum Hypertens 2015;29:64-8.

9. Parthaje PM, Unnikrishnan B, Thankappan KR, Thapar R, Fatt QK, Oldenburg B, et al. Prevalence and correlates of prehypertension among adults in urban south India. Asia Pac J Public Health 2016;28:93S-101S.

10. Galav A, Bhatanagar R, Meghawal SC, Jain M. Prevalence of hypertension among rural and urban population in Southern Rajasthan. Natl J Community Med 2016;6:174-8.

11. Kokiwar PR, Gupta SS, Durge PM. Prevalence of hypertension in a rural community of central India. J Assoc Physicians India 2012;60:26-9.

12. Satheesh BC, Iliyas MC. Prevalence of hypertension in a rural community of North Kerala, India: A cross sectional study. Int J Community Med Public Heal 2017;4:528-31.

13. Yuvaraj B, Gowda NM, Umakantha A. Prevalence, awareness, treatment, and control of hypertension in rural areas of davanagere. Indian J Community Med 2010;35:38-41

14. Kumar K, Kothari R, Kothari K, Garg S, Khandelwal MK, Gupta R. Prevalence of hypertesnion in an urban and rural area of Jaipur district. Int J Healthc Biomed Res 2013;1:120-6.

15. Todkar SS, Gujarathi VV, Tapare VS. Period prevalence and sociodemographic factors of hypertension in rural Maharashtra: A cross-sectional study. Indian J Community Med 2009;34:183-7.

16. Zachariah MG, Ankappan KR, Alex SC, Sarma PS, Vasan RS. Prevalence, correlates, awareness, treatment, and control of hypertension in a middle-aged urban population in Kerala. Indian Heart J 2003;55:245-1.

17. Vimala A, Ranji SA, Jyosna MT, Chandran V, Mathews SR, Pappachan JM, et al. The prevalence, risk factors and awareness of hypertension in an urban population of Kerala (South India). Saudi J Kidney Dis Transpl 2009;20:685-9.

18. Rao CR, Kamath VG, Shetty A, Kamath A. High blood pressure prevalence and significant correlates: A quantitative analysis from coastal Karnataka, india. ISRN Prev Med 2013;2013:574973.

19. Tee SR, Teoh XY, Aiman WA, Aiful A, Har CS, Tan ZF, et al. The prevalence of hypertension and its associated risk factors in two rural communities in Penang, Malaysia. IeJSME 2010;4:29-40.

20. da Costa JS, Barcellos FC, Sclowitz ML, Sclowitz IK, Castanheira M, Olinto MT, et al. Hypertension prevalence and its associated risk factors in adults: A population-based study in Pelotas. Arq Bras Cardiol 2007;88:59-65.

21. Dwivedi S, Gonmei Z, Toteja GS, Srivatsava N, Vikram NK, Rao S, et al. Prevalence of hypertension among adult population in slums of West Delhi. Asian J Pharm Clin Res 2017;10:350.

22. Ma SM, John J. Assess the prevalence of hypertension and knowledge regarding the prevention of stroke. Asian J Pharm Clin Res 2017;10:177-80. 